\title{
Seasonality and Ultrapoverty
}

\author{
Michael Lipton
}

\section{The Distinction between Poor and Ultra-poor}

Ultra-poor people are those who live in ultra-poor households. These are households with so little income per consumption unit that - if they adopt spending patterns (both among foods and as between them and non-foods) typical of their household size, composition and income - they are in a typical week able to eat so little food as to be a significant risk of not meeting their dietary energy requirement. In yearround or seasonally-spaced surveys, ultra-poor households, as a proportion of all households in any group, can be estimated by finding the proportion who follow the 'two 80 per cent rule': i.e. the proportion eating below 80 per cent of FAO/WHO (1973) weightadjusted dietary energy requirements, despite spending at least 80 per cent of income on food. Although for most low-income countries only 2-5 per cent of persons, in typical surveys not carried out in acute famines, either suffer from grade III anthropometry or fall into severely undernourished groups [Bengoa and Donoso 1974; Keller and Fillmore 1983] — and although it is only severe undernourishment that is linked to functional impairment [Lipton 1983] many more people are at risk of falling into such groups if bad life events, years, and/or seasons overlap or coincide. For most low-income countries, 10-20 per cent of people appear to fall into these ultra-poor groups, i.e. to follow the 'two 80 per cent' rule at any given moment of survey; such people, and especially their children, would be at quite substantial risk of descending into the severely undernourished 2-5 per cent, if their ultra-poverty were long sustained.

There are quite sharp turning points in food behaviour [Rao 1981; Lipton 1983a, 1985a; Edirisinghe and Poleman 1983] as between the ultra-poor, who follow the 'two 80 per cent' rule, and everybody else, including the moderately poor. Only the ultra-poor appear to maintain the ratio of food outlay - and even of outlay on coarse, low-cost energy sources - to income, when they become a little better off. Also the ultra-poor have sharply higher child/adult ratios; and are especially likely to be landless, or (in semi-arid areas) to operate below five acres or so. The ultra-poor also differ in certain labour-market characteristics. Although, even among the poor, lower income induces higher participation in work, this does not work among the ultra-poor, perhaps because they are too often hungry or ill. Also the ultra-poor, being more of ten dependent on casual labour than are other groups, show higher unemployment - but the places, years and seasons of substantially higher unemployment feature only slight reductions in labour supply (participation), and therefore somewhat lower real wage-rates [Lipton 1983a, 1983b, 1983c, 1985b].

If the ultra-poor are at much greater risk, especially of lasting harm to under-fives, from undernutrition and if their conditions make a normal response to investments or incentives, e.g. via raised workforce participation, specially difficult, and appear to mandate a 'food first' approach - then the separate identification of these ultra-poor households is crucial for the success of targeted policies against poverty. For example, in Kenya, areas with only slightly above average incidence of poor people have much greater measured severity of poverty [Greer and Thorbecke 1986], probably indicating a much greater proportion of ultra-poor (among the poor as a whole) than in other areas. These very poor areas, at least a priori, appear likely to be risky and unirrigated; the effects of seasonality, in such areas especially, upon the ultrapoor therefore merits close attention.

\section{Seasonal Differentiation}

Very interesting inferences are suggested by $\mathrm{Dr}$. Emmy Simmons's work on three villages in northern Nigeria [Lipton 1983a:42]. Non-poor households there show no relationship of calories per consumption unit to seasonal instability. Those with very low income per consumption unit - who normally average below $2,200 \mathrm{kcal}$ per consumption unit per day over the year - show some tendency to suffer

IDS Bulletin. 1986. vol 17 no 3, Institute of Development Studies. Sussex 
from greater seasonal variation as average intake declines. For those who are at slight risk of undernutrition, with intakes of dietary energy between 2,200 and $2,700 \mathrm{kcal}$ daily, this intake is very weakly correlated with income per consumption unit; they also show a strong negative link between low intake and seasonal instability.

This suggests that the severity of nutrition risk among the ultra-poor is linked to both hunger and seasonal instability. However, it also suggests that the apparent degree and indeed presence of caloric inadequacy among moderately poor people - who seem at first glance to have nutritionally borderline intakes of calories - is really due largely to choices, corresponding to differences in requirements, rather than to severe hunger (which one would expect to be income-linked in its intensity within the group counted as being at slight risk) or to average yearround income. The capacity to keep out of ultrapoverty may partly depend on adjustment mechanisms which permit persons within a group, who have relatively low average of intake to requirements, to adjust more effectively in seasons when that intake declines, because of falling intakes, rising requirements or both. Such adjustment seems to work for the group of persons at slight risk of undernutrition, but not for the group at high risk, as the above relationships indicate. Those at high risk overlap fairly closely, in these northern Nigerian villages, with those following the 'two 80 per cent rule'. A related finding in Matlab, Bangladesh, is that landless mothers showed both lower average dietary energy intake and greater seasonal fluctuation than did mothers with land [Chambers, Longhurst and Pacey 1981:59].

What of seasonality in labour income, the largest part of most poor people's incomes? Age- and sex-specific participation rates, real wage-rates, and unemployment all tend to fluctuate seasonally, and to do so most seriously for casual workers, females, and the ultrapoor. In the Indian National Sample Survey in 197778 , adult female participation rates fell nine per cent in rural areas, but six per cent in urban areas, from the July-September, 1977, seasonal peak to the AprilJune, 1978, trough; adult male rates fell by only three per cent and one per cent respectively. These comparative patterns are confirmed by State and village data, especially for casual workers [Lipton 1983b].

There are interactions between seasonal fluctuations in participation rates and in employment. The latter are also worst for the poorest people, since these are residual workers; in slack seasons, small farmers can adequately supply their labour requirements with family workers, and tend to lay off casual (landless) employees first - especially women — so as to minimise search and supervision costs of labour. (Such employees are also likeliest to be undernourished, and hence to show low labour-productivity, in the slack season.) In the 18 poorest households in four villages in Gujarat, adult-days in the workforce, as a proportion of all adult-days, fell from 38 per cent (peak) to 32 per cent (trough); in the best-off eight households in these villages, all with no participating female workers, the corresponding proportions of adult-days remained steady, at $43-45$ per cent, from peak to trough [Lipton 1983b:35]. These patterns are broadly confirmed in northern Nigerian villages.

The policy implications, in respect of building up slack-season female employment (for example with public works schemes), require caution. We find a serious slow-down in weight gain, among children aged less than 18 months, in the slack season in Shubh Kumar's study in Kerala, India - but this slow-down happens only among children whose mothers are in the workforce but outside the home enterprise, i.e. the poorest, who must rely on casual employment rather than self-employment [Kumar 1977]. Indeed, extra female income appears to assist slack-season child nutrition only if earned in the family enterprise [Kumar 1977:33].

Due to 'disguises' such as slack-season expansion of cattle care and domestic work, unemployment fluctuations are understated even in carefully collected village-level data. However such fluctuations remain significant, and affect the poorest worst, partly because - as we have seen - in slack seasons employees from poor households are 'crowded out' by the self-employed on small-to-medium family farms. This also happens in bad years; in the 1974-75 drought, in six villages of Gujarat, there was a fall of 55 per cent in family labour use from the previous year's level, but of 88 per cent in casual labour [Lipton 1983b:57]. However, generally, slack-season labour supply (as measured by the workforce participation rate) falls less than demand (as measured by the proportion of participants finding employment), so that real wage-rates fall alongside both (given that the elasticity of labour supply is not much below that of labour demand). Casual labourers, the most likely to be in ultra-poor households, tend to experience most acutely this seasonal conjunction of low employment, participation, and wage-rate.

What compensatory seasonal policies might exist? Irrigation, and seasonal compensatory employment schemes like Maharashtra's Employment Guarantee Scheme, often appear to raise employed time most for women, casual workers, and people from low statusgroups [Lipton 1983b:84-5]. Also, price compensation may be possible. Matlab data show rice prices highest, and household cereal stocks lowest, when seasonal 
wage-rates and employment are least, and this is confirmed for Bangladesh [Chambers, Longhurst and Pacey 1981:55, 89-90]. Modern varieties of cereals are often associated with some declines in the seasonal variability of outputs, because they often do best in irrigated conditions outside the main (rainy) cropping season. The resulting price stabilisation across seasons (which can be supplemented by public food grain releases in seasons of scarcity, if output growth due to modern varieties has permitted stockbuilding, as in India) can reduce seasonal vulnerability for the poor - which helps them even in parts of the country where the modern varieties have not prospered, but can be purchased, at less inflated prices than previously, in slack seasons or bad years.

\section{Is Sub-Saharan Africa Different?}

SSA generally has more extreme seasonality, but less inequality among the rural poor, than other developing areas. Seasonality is generally more extreme than in Asia in comparable semi-arid tropical zones, partly because there is less irrigation in SSA, partly because its porous, sandy soils retain less moisture. Offsetting this, the tropical rainforests of SSA may suffer from even less seasonality than elsewhere, because these are in general less exploited, at least than their Asian counterparts - and larger proportions of rural people depend on rainforest cultivation in Africa than elsewhere; but population growth and shortening fallows render this compensation less and less important as time goes by. Everywhere, water control seems to be less in Africa below three per cent of crop land is irrigated, as against over 30 per cent in Asia. Moreover long distances and bad transport systems impede seasonal corrections by way of movements of inter-regional (price-compensating) grain, and even of labour. At least since 1960, experience suggests that African climates are less predictable, more prone to greater harshness in bad years, and more liable to successive bad years, than Asian climates. All this reinforces the harm done by a given degree of seasonal instability. Moreover, in much of SSA, seasonal (and other) variations impinge more directly on poor people than is the case in South Asia, because a larger proportion of poor people retain usufructuary rights over cultivated land, and fewer have non-agricultural employment income. Furthermore, tribal tenure rights deny poor African farmers the 'last resort' of their Asian counterparts in really bad times, viz. mortgage. For all these reasons it is not surprising that African smallholders are much more prone to use intercropping to reduce risks than are Asian smallholders, and also to select crops with low seasonal specificity (roots and tubers in many cases), or low vulnerability to moisture stress (millet, sorghum), as compared with their Asian counterparts who try to select wheat or rice as main crops, soil and water permitting.

However, population growth in sub-Saharan Africa is eroding many of the differences - favourable and unfavourable - between its regions and similar ones in Asia. Slash-and-burn cultivation is less and less possible. A growing proportion of rural people comprises (a) landless or near-landless labourers, residual employees if in agriculture and hence especially vulnerable to seasonal and other fluctuations in the demand for labour; (b) farmers with individual claims on land rights, able to sell or mortgage land in time of stress. Crop-mixes are shifting (with urbanisation, food aid, and research biases) towards maize, rice and wheat, with more specific dated water requirements, and therefore more seasonal vulnerability, than the older crops and mixed-cropping systems.

As Africa's person/land ratio gets closer to Asia's, the 'Africa-damaging' differences in respect of vulnerability to seasonal stress should also be reduced. But the latter reduction requires public spending in support of the farm sector, in response to the new factor ratios. Such spending is constrained by urban bias much more extreme than in Asia; by severe shortages of funds for recurrent public outlays; and by foreign and other pressures towards 'price purist', expenditure-reducing public-sector policies. Hence there is rather little spending on the watermanagement, or even on the improvement of intrarural road systems, that might reduce seasonal vulnerability in Africa.

Bad seasonal impacts on poor people, like other 'agrohealth' issues, urgently need research on how to adapt responses to rapidly rising person/land ratios. What are the counter-seasonal options in the context of a continent-wide shift from area-expanding to yieldexpanding technology? The latter, in South Asia, has actually increased the coefficient of variation of yearly food output at national levels, but this is due to the concentration of (rising) output in a few nearby areas, dependent partly on irrigation but partly also on rainfall, and therefore covariant. Increases in fertiliser use, and most shifts towards modern seed varieties, increase 'worst-case' output-per-year for any given farm - even if that rather unimportant number, the coefficient of variation of national output, goes up. The damage done by an unexpectedly bad season should therefore be reduced by this sort of researchlinked intensification. But neither the increases, nor the improved levels of food reserves associated with a shift to modern varieties, can be achieved without substantial spending on agricultural research and on input supply and delivery, in most areas probably including at least micro-level irrigation systems. 


\section{Some Possible Areas of Remedy}

I should like to follow up the above remarks with something which is at best a set of notes towards a research agenda, that may stimulate others. The question is: how can one reduce the extent to which seasonality leads to increases in ultra-poverty? Several forms of adaptation to seasonal stress, by people already at risk, are possible.

First, food behaviour could be adapted. In an unexpectedly bad season, it may become possible for different groups of poor people to raise their ratios of consumption to income, of food to consumption, or of cheap (e.g. reserve-crop root) consumption to food. It may become possible for the potentially ultra-poor to escape their fate by adapting the timing of work, or of meals, or the places of work, to reduce the amount of calories required and/or to improve the conversion efficiency of food into work, although experts disagree about the extent to which individuals differ, over time, in their metabolic rates per $\mathrm{kg}$ - or can adapt their rates to increase food-to-work conversion efficiency in times of nutritional stress; how much adaptation is possible, among whom, for how long, and what measures might be taken by individuals or societies to improve benign adaptations to nutritional stress? It may also be possible to improve the intra-family food distribution in times of seasonal stress. Some of these strategies are doubtless adopted by poor people seeking to cope with bad seasons, but not all people adopt the best strategies in each bad season; perhaps some can learn from others, or can be helped by outside systems to do so.

Second, households in seasonal stress may be able to respond by adapting their use of factor inputs. Work timing, duration, type, or search behaviour may be adaptable between peak and slack seasons, or among household members in seasons of nutritional stress. If assets are owned, it may be possible at some cost to shift probable income from assets into the more stressful, or less secure, part of the year. Plainly, in environments where there are no major long-term trends of change, poor households are likely to learn such adaptive techniques by themselves - they must, to survive. But few environments are as static as this, and indeed policy itself does much to change them, often in ways that destroy traditionally learned methods of seasonal coping. Also, many of the poorest children do not at present survive seasonal stress; and many of the more adaptable adults either migrate or enrich themselves enough to reduce its impact, leaving the burdens to fall on those who remain in the potentially ultra-poor groups.

A third possible area of adaptation concerns seasonal migration. Often, seasonal migrants are the poorest and most oppressed of groups. Yet anti-poverty policy has seldom made effective contact with them. Further, Indian experience suggests that seasonal migration is a major outlet for people - e.g. landless or nearlandless labourers moving from Bihar to the Punjab for work - who would otherwise be much poorer; policies that subsidised or otherwise encouraged migration of labour, instead of mechanisation to displace labour, could have major beneficial seasonal effects. Problems of schooling and health for children, whether they accompany the seasonal migrants or are left behind, need careful attention, however.

Fourth, it would be worth looking at the possibility of adapting methods of seasonal financial-cum-land management. When a really bad year comes along, in the most difficult seasons, many people are pushed over into ultra-poverty by being compelled to sell or mort gage the little land they have. Can alternative and less onerous methods, at least providing some effective competition against the small number of local moneylenders, be found in such circumstances?

Finally, it would be worth asking whether common property resources, such as access to grazing, water, thatch grass and fuels, are - or can be rendered - less 'seasonal' than private property resources. Work done by Jodha in Rajasthan confirms that common property resources are a much larger part of income for the very poor than for the better-off - but that income from common property has been eroding rapidly in the last 15 years or so [Jodha 1983]. The analysis of common property management and protection is among the many parts of our subject that needs to take on a seasonal tinge, if the access of very poor people to basic food requirements in difficult times is to be safeguarded and improved.

These are admittedly scrappy 'thoughts of a dry brain in a dry season'. Perhaps there is an analogy between seasonal studies and women's studies. In both cases the impact and effectiveness of social scientists will be greatly reduced, if we make a little ghetto for seasonal studies or women's studies. In the case of seasons, our entire analysis of the economics, sociology and politics of agriculture and the rural economy - and of its relations with the city, about which I have said almost nothing here - needs to be permeated with an awareness that impact on the very poor matters most in the seasons of greatest risk, and is somewhat less important in the more well-favoured times of the year.

\section{References}

Bengoa, J. M. and G. Donoso, 1974, 'Prevalence of proteincalorie malnutrition, 1963-1973', PAG Bulletin, vol 4 no 2, pp 24-35

Chambers, R., R. Longhurst and A. Pacey (eds), 1981, Seasonal Dimensions to Rural Poverty, Frances Pinter, London 
Edirisinghe, N., and T. Poleman, 1983, 'Behavioural thresholds as indicators of perceived dietary adequacy or inadequacy', Cornell International Agricultural Economics Study No 17, Ithaca, NY

Greer, J., and E. Thorbecke, forthcoming, 'Food poverty profile applied to Kenyan smallholders', Economic Development and Cultural Change

Jodha, N., 1983, 'Market forces and the erosion of common property resources', Paper presented at the International Workshop on Agricultural Markets in the Semi-Arid Tropics, ICRISAT

Keller, W. and C. M. Fillmore, 1983, 'Prevalence of proteinenergy malnutrition', World Health Statistics Quarterly, vol 36 pp 129-67

Kumar, S. K., 1977, 'Role of the household economy in determining child nutrition at low-income levels: A case study in Kerala', Cornell University Occasional Paper No 95, Ithaca, NY
Lipton, M., 1983a, 'Poverty, undernutrition and hunger', World Bank Staff Working Paper No 597, Washington DC

-1983b, 'Labour and poverty', World Bank Staff Working Paper No 616, Washington DC

-1983c, 'Demography and poverty', World Bank Staff Working Paper No 623, Washington DC

- 1985a, 'Possibilities of reduced dietary energy requirements and of adaptation to low intakes: implications for economics and for policy', World Nutrition Society Conf., Brighton (mimeo)

-1985b, 'Land assets and rural poverty', World Bank Staff Working Paper No 744, Washington DC

Rao, V. Bhanoji, 1981, 'Measurement of deprivation and poverty based on the proportion spent on food: an exploratory exercise', World Development, vol 9 no 4 , pp 337-53 